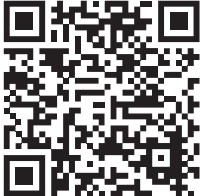

* Titular de la División de Educación Continua en el Instituto Mexicano de Seguro Social.

Correspondencia: JOSC drintervista@gmail.com Conflicto de intereses: No existe conflicto de intereses.

Citar como: Ojino SGJ. Atención de pacientes con COVID-19 en el consultorio médico. Rev CONAMED. 2020; 25(supl. 1): s4-s74. https://dx.doi. org/10.35366/97343

Financiamiento: Ninguno.

Recibido: 13/11/2020.

Aceptado: 13/11/2020.

\section{Atención de pacientes con COVID-19 en el consultorio médico}

\author{
Care of patients with COVID-19 in the doctor's clinic \\ Jesús Ojino Sosa García*
}

\section{RESUMEN}

Dentro de las manifestaciones clínicas de los pacientes con COVID-19 están los síntomas neurológicos y mentales. Es importante diferenciar en el consultorio médico de primer contacto los diversos signos y síntomas que pueden confundirse con alguna otra entidad nosológica. Los pacientes con COVID-19 se catalogan principalmente en: casos leves, moderados, graves y críticos. La importante diferenciación de cada uno de ellos es esencial en el primer contacto de atención, ya sea en el triaje, consultorio médico o en el servicio de urgencias, los estudios de laboratorio o gabinete pueden orientar a los posibles riesgos o complicaciones de los pacientes diagnosticados con COVID-19 y el manejo que se dará de acuerdo con su gravedad.

Palabras clave: COVID-19, atención primaria, manejo de pacientes.

\begin{abstract}
Among the clinical manifestations of patients with COVID-19 are neurological and mental symptoms. It is important to differentiate in the first contact doctor's office the various signs and symptoms that can be confused with some other nosological entity. Patients with COVID-19 are classified mainly in: mild, moderate, severe and critical cases. The important differentiation of each of them is essential in the first care contact, whether in triage, medical office or in the emergency service, laboratory or office studies can guide the possible risks or complications of diagnosed patients with COVID-19 and the management that will be given according to its severity.
\end{abstract}

Keywords: COVID-19, primary care, patient management. 


\section{ANTECEDENTES}

Hace poco más de cinco meses se detectó el primer caso de coronavirus en nuestro país. México se ha posicionado ya como el sexto país con más casos confirmados así como en el tercer lugar en mortalidad, aportando más de 48, 000 casos de muerte en nuestro país, lo cual resulta un poco preocupante derivado de que a pesar de las estrategias que se han implementado por parte de la Secretaría de Salud a nivel federal y estatal no se ha logrado mitigar el brote de la pandemia por COVID-19 en nuestro país.

Aunado a lo anterior, resulta esencial que nuestra población demande la atención a la salud de otras entidades no relacionadas con el coronavirus como las enfermedades crónicas no transmisibles, el embarazo, salud mental, entre otras. A dichas entidades es necesario darles continuidad para tener un control y prevención de las mismas durante el proceso de la atención de nuestra población.

Entre los profesionales de la salud existe una alta incidencia de contagios, se han reportado cifras de más de 42,000 aproximadamente que equivalen a cerca de $22 \%$ del total de los casos que se han registrado en nuestro país, de aquí deriva la importancia de establecer estrategias para prevenir y controlar las infecciones.

Esta enfermedad surgió a finales de diciembre de 2019 en Wuhan, China donde se reportaron 44 casos de neumonía de etiología desconocida que posteriormente se denominaría, una vez que se identificó el virus responsable de la enfermedad, SARS-CoV-2 y que se asocia a un síndrome respiratorio agudo grave por coronavirus tipo 2 llamado coronavirus o COVID-19.

El coronavirus pertenece a una familia de virus ARN de una sola cadena, provoca una serie de entidades desde enfermedades respiratorias que son las más frecuentes, pero también puede llegar a afectar a nivel entérico, hepático o neurológico e iniciar con signos y síntomas que podrían confundirse con alguna otra entidad a nivel del sistema nervioso central.

Los coronavirus no son los primeros que se presentaron durante este año y a fines del año anterior, sino que ya ha habido antecedentes relacionados con otras entidades epidemiológicas como el SARS-CoV que afectó a más de 8,000 personas con una mortalidad de 10\% y también el MERS-CoV con afectación a más de 800 personas con una mortalidad de hasta 35\%.

EI SARS-CoV-2 pertenece al género de betacoronavirus que se identifica no solamente en humanos, sino también en murciélagos y otras especies silvestres con las que pudiéramos tener contacto en algún momento y ser susceptibles de contagio por esta entidad.

\section{PRESENTACIÓN CLÍNICA}

\section{Mecanismos de transmisión}

Estudios epidemiológicos y virológicos sugieren que la transmisión ocurre principalmente por tres aspectos: de personas sintomáticas a otras en contacto estrecho, a través de gotas respiratorias y por el contacto directo con personas infectadas. Otra de las grandes desventajas que tenemos ante este virus es el contacto con objetos o superficies contaminadas dado que la vida de este virus puede perdurar hasta por horas en algunas superficies y esto predispone a tener mayor posibilidad de contagio.

El periodo de incubación de la enfermedad por COVID-19 entre la exposición del virus y el inicio de los síntomas puede ser de cinco a seis días o hasta 14 días para que el paciente presente síntomas; sin embargo, es importante recalcar que en este periodo presintomático, que puede ser de uno a tres días, es posible que algunas personas contagien la enfermedad, de ahí la relevancia de que existan portadores asintomáticos o que se encuentren en un periodo presintomático durante el cual distribuyen y dispersan el virus afectando a mayor cantidad de población y sobre todo a la más vulnerable.

La detección del virus es de hasta 20 días en un rango de 17 a 24 días y en algunos casos se puede detectar hasta 37 días después del contagio, de tal manera que en estas personas, a pesar de que su carga viral puede ser de mayor a menor concentración, se puede encontrar un mes después la presencia del virus.

\section{Manifestaciones clínicas}

De acuerdo con la primera serie que se publicó en China de 138 pacientes, en la cual el periodo de 
incubación fue de uno a 14 días con un rango entre tres y siete días, los signos más frecuentes fueron la presencia de fiebre hasta en $98 \%$ de los casos, manifestaciones generales como fatiga, anorexia, mialgias, tos seca, expectoración, disnea, faringitis y otras menos frecuentes, pero que también es importante tomar en cuenta como la presencia de diarrea, náuseas, cefalea, vómitos y dolor abdominal.

Existe una diversidad de signos y síntomas, gran parte de ellos inespecíficos, y que pueden llegar a confundirse con alguna otra entidad nosológica que es importante diferenciar de algunas enfermedades que se pueden sobreponer con el COVID-19.

Dentro de las manifestaciones clínicas de los pacientes con COVID-19 están los síntomas neurológicos y mentales, por ejemplo, la presencia de ansiedad y depresión es más común en pacientes hospitalizados que puede ser desde 34 hasta 28\% respectivamente, la presencia de delirium o agitación es más frecuente en los pacientes en unidades de cuidados intensivos hasta en 65 y $69 \%$, por tanto, dos de cada tres pacientes hospitalizados o en terapia intensiva pueden llegar a presentar estos síntomas neurológicos.

Dentro de estos síntomas neurológicos, los que más comúnmente se detectan en población abierta son anosmia y disgeusia, pero también puede llegar a presentarse ansiedad, depresión y trastornos del sueño; asimismo, es importante resaltar que de acuerdo con la tendencia que hemos observado con respecto a la presencia de anosmia y disgeusia, hay una correlación con el diagnóstico de COVID-19, es decir, existen altas posibilidades de salir positivo en la prueba para la determinación del SARS-CoV-2.

Estos signos y síntomas son menores y más leves en los pacientes pediátricos que en los adultos, de ahí que esta enfermedad es muy benevolente con los niños, pero a su vez esto repercute en que ellos sean también portadores del virus y puedan contagiar a mayor cantidad de personas.

La Organización Mundial de la Salud (OMS) resume todos los signos y síntomas que se mencionan, pero sobre todo cuáles son los factores de riesgo de que un paciente de enfermedad leve o moderada pueda progresar a una enfermedad grave.

\section{COMORBILIDADES}

En China, por ejemplo, una de las comorbilidades más frecuentes fue que uno de cada tres pacientes tenía hipertensión, enfermedades cardiovasculares, diabetes y otras como neoplasias o enfermedades cerebrovasculares.

En los Estados Unidos, por ejemplo, también la entidad más frecuente en $56 \%$ de los casos fue hipertensión, en segundo lugar obesidad y en tercer lugar diabetes.

En México, la comorbilidad más frecuente es la presencia de obesidad, lo cual está en correlación con el hecho de que tenemos como país el primer lugar en obesidad a nivel mundial y esto predispone a que las personas no solamente se contagien más, sino también a que haya complicaciones con respecto al COVID-1; en segundo lugar está la hipertensión, al igual que en el resto de los países y en tercer lugar, la presencia de diabetes, otra de las entidades también muy frecuentes en nuestro país y que predispone al desarrollo de COVID-19.

\section{Manifestaciones clínicas}

Los pacientes con COVID-19 se catalogan en cuatro escenarios posibles: los casos leves, los casos moderados, los casos graves y por último los casos críticos.

Diferenciar cada uno de ellos es importante porque quienes que están en primer contacto ya sea en triaje, en consultorio médico o en el servicio de urgencias tienen que hacer una diferenciación entre la clínica que presenta el paciente y el escenario al cual se atribuye dicha entidad.

Los casos leves son aquellos pacientes con sospecha o caso confirmado por COVID-19, constituyen $40 \%$ de los casos, es decir, los pacientes que van a tener muy pocos síntomas o asintomáticos y van a cumplir con la definición de caso por COVID-19. Estos pacientes no tienen evidencia de neumonía ni de hipoxemia, es eso lo que los va a diferenciar de los casos moderadosy pueden no tener ningún síntoma o solamente tener anosmia y disgeusia o algún síntoma general que puede ser controlable con analgésicos o antipiréticos.

Los casos moderados también afectan a 40\% de los casos, esto quiere decir que $80 \%$ de los casos con COVID-19 son de leves a moderados y se 
pueden atender desde el domicilio o en lugares apropiados para que lleven a cabo la convalecencia. Aquí hay presencia de neumonía, va a haber signos clínicos de neumonía como fiebre, tos, disnea, taquipnea, pero sin datos de neumonía grave, lo que incluye la presencia de desaturación; al momento de medir la saturación en estos pacientes deberá ser igual o mayor de $90 \%$ al aire ambiente, es decir, sin oxígeno suplementario.

El diagnóstico en este caso puede ser clínico, radiográfico, por medio de una tomografía de tórax o a través de otras herramientas como el ultrasonido, lo que puede ayudar en el diagnóstico para identificar o excluir alguna otra complicación que se puede presentar en estos pacientes.

Los casos graves constituyen $15 \%$ del total de los casos y se asocian con la presencia de una neumonía grave, es decir, los signos clínicos de neumonía fiebre, tos, disnea y taquipnea, pero en este caso el paciente va a presentar desaturación con hipoxemia menor de $90 \%$ al aire ambiente y también va a presentar insuficiencia respiratoria con hasta más de 30 respiraciones por minuto.

Esto es lo que va a diferenciar un caso grave con neumonía de un caso moderado, y se puede atender en diferentes instancias dependiendo de la situación clínica de cada paciente.

De los casos con COVID-19, 5\% son pacientes críticos, es decir, son aquellos pacientes que evolucionan dentro de la primera semana de la afectación y cursan con neumonía o síntomas respiratorios que pueden ser nuevos o que se van deteriorando progresivamente.

Estos pacientes tienen alto riesgo de complicación como falla respiratoria aguda y síndrome de insuficiencia respiratoria aguda y en caso de que lleguen a presentar alguna coinfección, pueden cursar con sepsis grave, choque séptico y también pueden iniciar con enfermedad tromboembólica venosa, falla multiorgánica por la presencia de lesión renal aguda y falla cardiaca.

En la mayoría de estos pacientes, el principal órgano afectado es a nivel respiratorio y pueden llegar a presentar otras complicaciones menos frecuentes como a nivel renal, a nivel cardiaco o la presencia de eventos tromboembólicos venosos.

Estos pacientes críticos se van a referir a un siguiente nivel de atención, ya sea un segundo o tercer nivel de atención o áreas especiales que existen para atender este tipo de población con COVID-19, donde se les pueda dar el soporte que estos pacientes requieren en cuanto al cuidado crítico.

En general, ésta es la presentación clínica de los diferentes escenarios que podemos tener en los pacientes con COVID-19. Desde los casos leves hasta los casos moderados se van a estar atendiendo en un primer contacto o dentro del consultorio médico; es importante identificarlos y darles el manejo domiciliario para su atención con las manifestaciones de alerta.

La OMS define quién es un paciente crítico, qué complicaciones puede llegar a tener y qué es importante que analicemos y detectemos de manera oportuna.

\section{Factores de riesgo (Síndrome de Insuficiencia Respiratoria Aguda y muerte)}

No todos los pacientes que presentan caso leve, moderado, grave o crítico tienen mayor riesgo de mortalidad que otros porque, por ejemplo, la presencia de disnea es un factor importante que puede predisponer a complicaciones, mas no a mortalidad.

Hasta en 59\% de los casos las comorbilidades más frecuentes a nivel mundial son hipertensión y diabetes entre 27 y 19\%, pero en nuestro país, a diferencia de los Estados Unidos, China o de algunas series italianas publicadas, la obesidad es el principal factor de riesgo en cuanto a la afectación por el COVID-19. Las personas adultas mayores de 60 años de edad tienen un riesgo de $226 \%$ más de presentar riesgo de SIRA o de muerte en esta entidad.

Algunos datos de laboratorio que nos pueden orientar respecto a lo que puede suceder con nuestro paciente y el riesgo potencial de insuficiencia respiratoria aguda e incluso de muerte, son la presencia de neutrofilia hasta en $14 \%$ de los casos, la elevación de la deshidrogenasa láctica (DHL) hasta en $61 \%$ de los casos y la elevación del dímero D es significativa en $3 \%$ de los casos.

En nuestro país, la presencia de la escala SOFA alta asociada con disfunción orgánica y sobre todo el acompañamiento de lesión renal aguda en esta población son los factores que más se han asociado con riesgo de muerte.

Es importante que en el consultorio médico de primer contacto se reconozca a estos pacientes que 
se presentan como caso sospechoso o confirmado de COVID-19. Permanecer en alerta de los signos de emergencia como aumento en la dificultad respiratoria, presencia de coloración violácea o azul en labios y rostro, debilidad generalizada y progresiva, dolor persistente en el pecho, disminución de la saturación menor de 90\%, inflamación de extremidades, hipotensión, taquicardia, confusión, mareos, entre otros signos neurológicos, nos puede orientar a la posibilidad de que el paciente se está complicando y que es necesario que se reconozcan estando en casa o en algún centro de atención especial para llevar a cabo su convalecencia en los casos leves a moderados.

\section{ABORDAJE DIAGNÓSTICO-TERAPÉUTICO}

\section{Diagnóstico}

Uno de los puntos más importantes para el diagnóstico es el clínico; 40\% de los casos son los pacientes que pueden ser asintomáticos o tener síntomas leves de mal estado general, anosmia, disgeusia, fiebre, tos seca. En los casos moderados la presencia de neumonía que puede condicionar la disnea, fiebre, tos y el progreso de la entidad es lo que vamos a detectar y catalogar en nuestros pacientes.

Dentro de los estudios de laboratorio y gabinete que van a ser de gran utilidad, el estándar de oro para el SARS-COV-2 es la reacción en cadena de polimerasa en tiempo real (TR-PCR) de tracto respiratorio superior a nivel nasofaríngeo y orofaríngeo, que nos va a permitir detectar la presencia de este virus.

Algunos estudios de laboratorio que se han utilizado como marcadores que pueden orientarnos a posibles factores de riesgo de complicación de estos pacientes son, por ejemplo, la presencia de leucocitos normales con linfopenia, la elevación de marcadores como la DHL, el dímero D, fibrinógeno, estos últimos dos asociados con mayor riesgo tromboembólico. La presencia en la elevación de proteína C reactiva y ferritina en casos graves a críticos puede requerir de la determinación de estos marcadores para poder orientarnos respecto a lo que está sucediendo.

En cuanto a estudios de imagen, es de gran utilidad la radiografía de tórax si no tenemos acceso a una tomografía; lo que nos permite tener un panorama global de lo que está sucediendo anatómicamente a nivel pulmonar es la tomografía computarizada de tórax. El ultrasonido es otra herramienta; sin embargo, no todos los centros hospitalarios o consultorios cuentan con un ultrasonido para llevarlo a cabo, de tal manera que hoy por hoy hay pacientes que recurren prácticamente a la tomografía computarizada de tórax directamente para hacer el diagnóstico presuntivo del SARS-CoV-2.

Los hallazgos tomográficos que se pueden llegar a presentar son muy compatibles con los publicados con relación a lo que es el COVID-19. Otro dato importante es que no se recomienda el uso de anticuerpos contra el SARS-CoV-2 para el diagnóstico de infección reciente por COVID-19, ya que no significa que en ese momento se tenga el COVID-19, sino simple y sencillamente es la inmunidad que generan posterior a haber estado en contacto con el SARS-CoV-2, por lo tanto no es una herramienta diagnóstica para definir si el paciente cursa o no con la presencia del virus.

\section{Diagnóstico diferencial}

Otro de los puntos importantes a considerar en nuestro país es la presencia de sindemias y obviamente de las coinfecciones que se pueden llegar a presentar con el COVID-19, dentro de las más frecuentes serían dengue, influenza, chikungunya y en algunos otros estados o países de la región de las Américas la presencia de tuberculosis, fiebre tifoidea o de malaria que pudieran llegar a coexistir en conjunto con el COVID-19 y en ciertos momentos desorientarnos en cuanto al diagnóstico diferencial.

Es importante diferenciarlo, ya que en los casos graves a críticos pueden surgir las infecciones secundarias. Éstas pueden ser bacterianas, micóticas, entre otras, y que no necesariamente haya una sindemia.

Con base en las características clínicas de nuestros pacientes, y en algunos casos los estudios de gabinete, nos pueden orientar respecto a qué es lo que vamos a hacer. Si bien es cierto nuestra población va a acudir a consulta por «n» cantidad de padecimientos, en este momento no podemos dejar de lado la presencia del COVID-19. 


\section{Manejo de casos leves}

Los pacientes con casos leves no requieren hospitalización, en su mayoría el aislamiento puede ser en casa o en instalaciones asignadas para COVID-19, en algunos países como el nuestro existen áreas a nivel nacional o estatal asignadas para tal fin, donde los pacientes pueden ir a hacer su convalecencia y pasar los 14 días que se recomiendan en aislamiento para el manejo de esta entidad.

En los casos leves el tratamiento es sintomático; en caso de presencia de fiebre o de dolor el paciente debe llevar una alimentación adecuada, una hidratación apropiada y recordar siempre que ante la presencia de uno o más signos de emergencia pueden acudir a valoración en caso de que sea necesario o a través de las herramientas tecnológicas con las que contamos actualmente como una videollamada o un mensaje y poder alertar a los médicos o a quienes están al tanto de su evolución.

\section{Manejo de casos moderados}

El primer nivel de atención es una entidad que puede manejar estos casos, la mayoría de ellos no requieren hospitalización, se recomienda un aislamiento en casa o también en las instalaciones asignadas para COVID-19.

Se debe manejar un tratamiento sintomático para la fiebre o el dolor, una alimentación adecuada y una hidratación apropiada, pero en un caso moderado con presencia de neumonía es importante tomar en cuenta aquellos pacientes que pueden tener factores de riesgo para no sobrecargar con la hidratación, por ejemplo, en pacientes con insuficiencia renal crónica que no toleran las grandes cantidades de líquidos.

Hay que considerar que el aporte de oxígeno en estos pacientes puede llegar a bajar a menos de $90 \%$ y que podría recomendarse el oxígeno domiciliario; otra de las estrategias que se han venido implementando en los pacientes con neumonía moderada y también grave es la posición prono vigil, es decir, aquellos pacientes cuya tomografía muestre áreas de consolidación y en quienes la posición prono vigil les permita hacer un mejor intercambio de oxígeno, y que los requerimientos así como el esfuerzo manifestado a través de la disnea sean menores.
En estos pacientes que requieren aporte de oxígeno, se puede valorar el uso de esteroides. De acuerdo con los últimos estudios reportados como el estudio RECOVERY, en el cual se evaluó el uso de la dexametasona, puede ser de gran utilidad en pacientes con una evolución mayor de ocho días y que tengan oxígeno suplementario, ya sea por puntas nasales, mascarillas con reservorio, o de alto flujo, entre otros.

En los pacientes con casos leves que no requieren oxígeno no está indicada la administración de esteroides, en particular de la dexametasona, es decir, debemos individualizar qué pacientes se van a beneficiar con el uso de estos medicamentos, y quiénes cumplen con estas dos características en cuanto al tiempo y el uso de oxígeno suplementario.

En pacientes con alto riesgo de deterioro se prefiere un aislamiento hospitalario, es decir, un paciente que tiene factores de riesgo, de edad mayor de 60 años, el paciente diabético, hipertenso, obeso, probablemente es un potencial complicable y se prefiere que en vez de estar en casa se pueda manejar en un centro hospitalario y estar más al pendiente de su evolución y así tener un mejor manejo de esta población.

Otro punto importante es un algoritmo que se generó con la Organización Panamericana de la Salud para la atención de los pacientes en áreas remotas, pero que viene muy ad hoc porque se puede tropicalizar y adaptar al primer contacto en nuestra población, incluso en lo que es el consultorio médico.

Este algoritmo nos permite identificar a los pacientes de acuerdo con sus signos, síntomas y factores de riesgo. Los podemos manejar desde casa, en un área especial para los pacientes con COVID o si es un paciente que tiene datos de alarma, puede ser referido a un siguiente nivel de atención.

De tal manera que si decidimos manejar a estos pacientes de casos leves a moderados en casa, qué estrategias debemos implementar a través del aporte de oxígeno y cómo escalar de acuerdo con las necesidades de este paciente y los niveles de saturación desde lo que son puntas nasales, mascarillas de alto flujo, entre otros, y en qué momento debemos derivar a dichos pacientes.

Algo que ha venido afectando es que los pacientes cada vez llegan más tardíamente por temor 
o por diversos motivos a las unidades de atención y eso obviamente se traduce en que haya mayor riesgo de complicaciones y por ende de mortalidad.

De tal manera que es importante que sepamos en qué momento referirlos a otro centro hospitalario para que reciban atención y optimizar así el manejo, ya sea por el riesgo de tromboembolismo que presenta el uso de enoxaparina o de heparina no fraccionada, dexametasona, o el uso de oxígeno.

\section{Manejo de casos graves y críticos}

Los casos graves y críticos son pacientes que no van a llegar directamente a un consultorio, quizá a un contacto en un triaje o a un servicio de urgencias, ya que este tipo de pacientes desde graves hasta críticos requieren de otro tipo de manejo más específico y para esto existen documentos como la guía de práctica clínica de la Organización Mundial de la Salud o la guía de la Organización Panamericana de la Salud, la cual está tropicalizada a los países de la región con base en los recursos con los que se pueda contar para atender esta población.

\section{CRITERIOS DE REFERENCIA}

¿Cuándo derivar a un paciente que estoy consultando, que está en su domicilio, a un centro especializado o a un siguiente nivel de atención porque se requiere mayor soporte de oxígeno?

\section{Signos de deterioro}

Están aquellos pacientes que tienen signos de deterioro como alteración del estado de alerta, insuficiencia respiratoria aguda, dolor en el pecho de manera persistente, son pacientes deshidratados que también cursan con sepsis grave, choque séptico manifestado por hipotensión, taquicardia, etc., que requieren atención especializada ya sea un hospital de COVID o en una unidad de cuidados intensivos en los diferentes hospitales.

\section{Funciones}

Tenemos que hacer tres funciones en el primer nivel de atención, la primera es una atención centrada en respuestas a COVID-19, es decir, identificar, reportar, contener, manejar y referir al paciente que requiera un manejo avanzado a un siguiente nivel de atención.

Pero como primer contacto, no sólo nos vamos a enfrentar a pacientes con COVID-19 como parte de nuestra nueva normalidad, la población también demanda que sigamos atendiendo sus problemas de fondo como las enfermedades crónicas no transmisibles, evaluar o valorar la evolución del embarazo, salud mental, entre otros padecimientos, de tal manera que se tiene que mantener la continuidad de los servicios esenciales durante la transmisión comunitaria del COVID-19.

Por otro lado, también debemos propiciar las altas hospitalarias para ampliar la capacidad de los servicios hospitalarios en respuesta al COVID-19, es decir, aquellos servicios de cirugía ambulatoria, diálisis peritoneal, hemodiálisis que se siguen llevando a cabo; sin embargo, nos vamos a centrar en la primera función, es decir, cómo identificar, reportar, contener, manejar y referir a nuestros pacientes.

\section{Atención centrada en respuesta a COVID-19: identificar y reportar casos y contactos}

Significa apoyar en la búsqueda y detección temprana, identificar aquellos pacientes y sobre todo dar seguimiento a adultos mayores, a los casos y contactos que se tienen con ellos para tratar de ubicarlos y mantenerlos aislados en lo que pasa la cuarentena.

Realizar un pretriaje o triaje en pacientes con enfermedades respiratoriasy facilitar el diagnóstico tras la sospecha clínica de personas con COVID-19 según los protocolos que existen en cada país. Se deben identificar y reportar los casos y contactos, tener una red comunitaria para poder trabajar de manera conjunta y coordinada con otras entidades y con otras instituciones públicas del sistema nacional de salud, la atención presencial en el centro de pacientes en el primer nivel de atención y también la atención domiciliaria o centros de aislamiento, empleo de la telemedicina, las Ilamadas telefónicas o los telemensajes que son otras de las herramientas que hemos venido implementando para facilitar dar seguimiento a nuestros pacientes sin tener que desplazarse o estar en contacto con ellos y de alguna manera mitigar el riesgo de contagio a otras personas incluso a los propios trabajadores de la salud. 
Implementar estas estrategias a través de herramientas tecnológicas como el teléfono celular que permite hacer videollamadas o estar en contacto con mensajes con el profesional de la salud que le está dando seguimiento.

\section{Contención de la expansión}

Tratar de contener la expansión de la enfermedad, es decir, apoyar el aislamiento de los casos y contactos a que permanezcan en cuarentena, el aislamiento social que es una estrategia importante, que concienticemos a la población, que se sensibilice a la importancia de seguir este tipo de medidas para poder contener la expansión y obviamente a través de la comunicación y asesoría de las medidas de salud pública, desde la higiene de manos, el estornudo de etiqueta, el distanciamiento social, entre otras.

Para esto también requerimos la modalidad de activación de redes comunitarias, el uso de las tecnologías para telemensajes, Ilamadas telefónicas, apoyo intersectorial, siendo muy importante que exista comunicación entre las instituciones públicas per se y de igual manera con el medio privado para llevar un adecuado control de la expansión de estos pacientes.

\section{Manejo}

Por otro lado, hay que asegurar la atención en el manejo de estos pacientes, los cuidados que se requieren y el seguimiento domiciliario de las personas con síntomas leves o en aquellos pacientes con síntomas moderados en algún sitio especial de cuidados del paciente convaleciente así como proveer los medicamentosy dispositivos necesarios para llevar a cabo el seguimiento y monitoreo de estos pacientes.

Hacer énfasis en la promoción de las medidas de contención de la transmisión de este virus, la modalidad en la atención a domicilio, los centros de atención y el uso de tecnologías para llevar a cabo este punto.

Es importante que existan mecanismos de referencia a un nivel hospitalario superior, ya sea un segundo o tercer nivel de atención de pacientes con signos y síntomas de gravedad o aquellos pacientes con factores de riesgo y el uso de todas estas tecnologías para llevar a cabo la referencia de estos pacientes a un siguiente nivel de atención.

\section{Medidas de prevención y control de infecciones}

Los profesionales de la salud no están exentos del contagio de esta entidad en la atención de los pacientes con COVID-19, por ello es importante que implementemos medidas de protección, de control de las infecciones en cualquier entidad en la que nos encontremos, ya sea a nivel de triaje, en el consultorio médico, en el servicio de urgencias, en la unidad de terapia intensiva, en quirófano, etcétera.

Siempre hay que aplicar las medidas necesarias, dependiendo de los riesgos que pueda llegar a tener el paciente y dentro de ellas, cuáles son los objetivos de la protección: limitar la transmisión interpersonal, evitar la expansión del virus, reducir también las infecciones secundarias que pueden llegar a presentar en los pacientes y prevenir la transmisión tras eventos de amplificación que se pueden llegar a presentar en una entidad hospitalaria o en alguna otra área recreativa.

\section{Precauciones estándar}

Dentro de las precauciones estándar para tratar de mitigar la función del virus, la higiene de manos es una de las medidas más económicas que a veces subestimamos, pero que ha demostrado ser efectiva para reducir la transmisión del virus.

De acuerdo con la evaluación del riesgo, no vamos a usar el mismo equipo para toda la población, dependiendo del riesgo al cual estemos expuestos es lo que vamos a utilizar desde guantes, bata, mascarilla médica, protección ocular a través de gafas o caretas, entre otros. La higiene respiratoria, es decir, el estornudo de etiqueta es una medida también importante que se debe sumar.

La esterilización y la desinfección de los equipos médicos que se utilicen durante la atención como el estetoscopio, el baumanómetro, el escritorio donde estamos frente al paciente y sobre todo la limpieza del ambiente que es toda aquella área con la que estamos en contacto tanto con el paciente como con el profesional de la salud que brinda atención a esta población y que podría ser portador del virus, ya que éste tiene mayor capacidad de sobrevivir en ciertos medios, en algunos de ellos hasta por aproximadamente seis horas. 


\section{Precauciones: mecanismo de transmisión}

Para evitar el contagio por contacto, lo recomendado es que el personal use bata.

Para evitar el contagio por gotas, la mascarilla médica es más que suficiente, o en los procedimientos generadores de aerosoles como el de la intubación orotraqueal, la RCP, broncoscopia, entre otros procedimientos que pueden generar este tipo de aerosoles, se recomienda la mascarilla N95; cuando estemos en contacto con este tipo de población, lo ideal es que tengamos al menos los elementos esenciales como bata quirúrgica, batas, botas, gorro, gafas protectoras; dependiendo del tipo de aerosol, mascarilla médica o una N95 y el uso de guantes, se recomienda usar siempre doble guante.

Cuando se trate de un caso sospechoso o confirmado de COVID, se recomienda lo mínimo indispensable para evitar el contagio por gotas y el contacto directo del paciente: bata quirúrgica, botas, bata, gafas protectoras, gorro, mascarilla médica y guantes. En este caso, por la magnitud y la capacidad de contagio, la distancia que se tenga con el paciente es más que suficiente para evitar un contagio por gotas en los pacientes con sospecha o casos confirmados de COVID-19.

En situaciones en las que las medidas se tienen que ampliar por la presencia de procedimientos generadores de aerosoles, sumado a lo anterior, tenemos que utilizar sobre todo el equipo Tyvek ${ }^{\circledR}$ que es impermeable para evitar el contagio por la presencia de estos aerosoles. Lo ideal es usar un equipo completo para evitar el contagio, dependiendo de la población que tengamos, un servicio de urgencias, un servicio de terapia intensiva y cómo debemos aplicar las medidas.

En un consultorio médico con las precauciones estándar y sobre todo de contacto, el uso de botas nos protege ante un posible caso sospechoso o confirmado de COVID-19.

\section{Evaluación del riesgo}

Se tiene que evaluar el tipo de interacción que vamos a tener con el paciente, el modo de transmisión de la enfermedad y la cantidad de fluido corporal que se puede generar a través de ciertos procedimientos. Es así como se van a utilizar las diferentes estrategias.

\section{Principios generales del EPP}

La higiene de manos debe realizarse siempre aun con el uso de equipo de protección personal, el uso de guantes no sustituye el lavado de manos para evitar la transmisión de otras infecciones que pudieran complicar la evolución de los pacientes.

Retire o reemplace, si es necesario, cualquier pieza dañada o rota del equipo de protección personal, ya sea que el guante se haya roto, o que la bata, el gorro o nuestro cubrebocas no estén ya funcionando efectivamente. Una vez que concluyamos nuestra jornada, los procedimientos o el motivo por el cual usamos equipo de protección personal, vamos a retirarlo tan pronto como sea posible teniendo cuidado para evitar el contacto con la superficie posiblemente contaminada directamente con nuestra piel.

Es importante también, una vez que se retire el EPP desechar todos los artículos que se hayan utilizado en el equipo de protección personal, y nuevamente una vez terminado el proceso de retiro del equipo de protección personal lavarse las manos siempre al inicio y al final del procedimiento.

Estos son los diferentes escenarios en los que podemos usar el equipo de protección personal según el tipo de atención, si estamos en triaje podemos lavarnos las manosy usar mascarilla médica; si vamos a tomar muestras para diagnóstico laboratorio se recomienda la higiene de manos, el uso de guantes, utilizar el N95, protección ocular o facial y batas.

En un caso sospechoso o confirmado con procedimientos que no generan aerosoles podemos utilizar todos los insumos excepto el N95, ahí podemos utilizar la mascarilla médica, a diferencia del caso sospechoso o confirmado que serán procedimientos generadores de aerosoles, se recomienda aplicar todas las medidas y vamos a sustituir la mascarilla médica por el N95 para tratar de evitar la transmisión a través de los aerosoles.

Éstos son los equipos de protección personal que vamos a implementar (mascarilla, cubrebocas, guantes, protección ocular, batas), dependiendo de la actividad o atención que le vayamos a dar a nuestros pacientes. Es muy importante saber ponerse el equipo de protección personal que es 
seguro porque no hay manera de que esté contaminado, también es importante retirar cada uno de estos elementos siempre evitando el contacto directo con la piel para no contagiarse de COVID-19.

\section{CONCLUSIONES}

En la atención de los pacientes en primer nivel de atención es importante saber qué hacer, detectar y aislar los casos sospechosos o confirmados por COVID-19 con la finalidad no solamente de contener, sino también de manejar la enfermedad. Los casos leves se pueden tratar en casa y no requieren más que manejo sintomático.

Es importante evaluar el riesgo y el equipo de protección personal a utilizar anteponiendo siempre la seguridad del personal de salud, nosotros como profesionales de la salud nos gana el espíritu por atender a los pacientes y a veces olvidamos ponernos algo tan básico como la mascarilla, la bata, los guantes; aquí lo importante es salvaguardar la seguridad del profesional de la salud ante cualquier escenario que se pueda presentar en un caso sospechoso o confirmado por COVID-19.

Los pacientes con factores de riesgo de enfermedad grave deben ser monitoreados de manera constante y ser referidos oportunamente al siguiente nivel de atención. No hay que dejar pasar el tiempo, a veces por no llevar a cabo el monitoreo, por dar oportunidad a que el paciente mejore con el tiempo, o a veces porque el paciente per se no quiere ir a un siguiente nivel de atención.

Hay que insistir en que la atención temprana y oportuna de estos pacientes impacta en el pronóstico y desenlace que puede llegar a tener. Emplear el monitoreo domiciliario para evaluar la evolución de los pacientes nos ayuda a que disminuya la exposición, la diseminación y el riesgo de contagio de más personas o incluso de los profesionales de la salud y esto ayuda a reducir la saturación de los establecimientos de salud.

Esto se realiza a través del uso de las herramientas tecnológicas para hacer videollamadas y mensajes u otro tipo de contacto con estos pacientes, para monitorear a través de estas herramientas la evolución que va teniendo el paciente y de esta manera evitar todo lo mencionado anteriormente.

Con la gran cantidad de información que existe a través de internet o de los comentarios entre colegas o vecinos, no se recomienda la profilaxis o tratamiento con antibióticos; en pacientes con casos leves el manejo es domiciliario, manejo sintomático que no requiere de ninguna otra intervención, tampoco se recomienda la profilaxis o el tratamiento con antibióticos en los pacientes de casos moderados, a menos que exista la sospecha de una infección agregada, ya sea bacteriana o fúngica, en estos pacientes que incremente el riesgo de deterioro, complicaciones y mortalidad.

Hoy por hoy no se recomienda el uso de cloroquina, hidroxicloroquina que puede ser con o sin azitromicina, antiparasitarios como ivermectina y nitazoxanida, antivirales como lopinavir, zanamivir, oseltamivir, algunos inmunomoduladores como tocilizumab, interferón, inmunoglobulinas, colchicina, entre otros.

A propósito de sustancias como el dióxido de cloro que ha estado en auge últimamente, hay posiciones de la Organización Mundial de la Salud desde la propia COFEPRIS de no hacer uso de este tipo de intervenciones en nuestro país, pues pueden condicionar a mayor daño y alteración en estos pacientes.

\section{AGRADECIMIENTOS}

Agradecimiento a los alumnos pasantes de servicio social MPSS Carmen Gabriela Jerónimo Gutiérrezy QFB Liliana Aguilar Castañeda de las licenciaturas de Medicina y Química Farmacéutica Biológica por su colaboración en la transcripción del texto.

\section{LECTURAS RECOMENDADAS}

1. Organización Mundial de la Salud. Los nombres de la enfermedad por coronavirus (COVID-19) y del virus que la causa. Disponible en: https://www.who.int/es/emergencies/ diseases/novel-coronavirus-2019/technical-guidance/ naming-the-coronavirus-disease-(covid-2019)-and-thevirus-that-causes-it

2. Organización Mundial de la Salud. Clinical management of COVID-19. $3^{a}$ edición. 2020. Di sponible en: http://www.who. int/publications///item/clinical-management-of-severeacute-respiratory-infection-when-novel-coronavirus(incov)-infection-is-suspected

3. Wang D, Hu B, Hu C, Zhu F, Liu X, Zhang J et al. Clinical characteristics of 138 hospitalized patients with 2019 novel coronavirus-infected pneumonia in Wuhan, China. JAMA. 2020; 323 (11): 1061-1069. 
4. Richardson S, Hirsch JS, Narasimhan M, Crawford JM, McGinn T, Davidson KW et al. Presenting characteristics, comorbidities, and outcomes among 5700 patients hospitalized with covid-19 in the New York City area. JAMA. 2020; 323 (20): 2052-2059.

5. Sosa-García JO, Gutiérrez Villaseñor AO, García-Briones A, Romero-GonzálezJP, Juárez-Hernández E, González-Chon O. Clinical Characteristics of Severe COVID-19 patients in an ICU in Mexico. Disponible en: http://dx,dol.org/10.2139/ ssm.3605185

6. Wu C, Chen X, Cai Y, Xia J, Zhou X, Xu S et al. Risk factors associated with acute respiratory distress syndrome and death in patients with coronavirus disease 2019 pneumonia in Wuhan, China. JAMA Intern Med. 2020; 180 (7): 934-943.

7. Sosa-García JO, Gutiérrez Villaseñor AO, García-Briones A, Romero-González JP, Juárez-Hernández E, GonzálezChon O. Experiencia en el manejo de pacientes graves con COVID-19 en una unidad de terapia intensiva. Cirugía y Cirujanos. 2020; 88 (5): 569-575.
8. Algoritmo Organización Panamericana de la Salud para atención de pacientes con COVID-19 en áreas remotas. Disponible en: http://iris.paho.org/ handle/10665.2/52501

9. Organización Panamericana de la Salud. Guías para el cuidado crítico de pacientes adultos graves con coronavirus (COVID-19) en las Américas. Disponible en: http://www.paho.org/es/documentos/guía-para-cuidadocritico-pacientes-adultos-graves-con-coronavirus-COVID19-americas

10. Organización Panamericana de la Salud. La adaptación del primer nivel de atención en el contexto de la pandemia de COVID-19: intervenciones, modalidades y ámbitos. 23 abril del 2020. Disponible en: http://www.paho.org/bitstream/ handle/10665.2/52223/OPSHSSHSCOVID-19200017spa. pdf?sequence=7\&isAllowed=y

11. Organización Panamericana de la Salud. Prevención y control de infecciones. Disponible en: http://www.paho. org/es/documentos-tecnicos-ops-enfermedad-porcoronavirus-covid-19\#prevencion-infecciones 